This is the peer reviewed version of the following article:

Journal of Clinical Nursing 26(1-2):248-257 2017]

which has been published in final form at

https://opus.lib.uts.edu.au/handle/10453/126277

This article may be used for non-commercial purposes in accordance with Wiley Terms and Conditions for Self-Archiving." 


\title{
Diabetes literacy and informal social support: A qualitative study of patients at a diabetes centre
}

\begin{abstract}
Aims and objectives

The research project aimed to explore the resources that patients diagnosed with type 2 diabetes drew upon to manage the disease in their daily lives
\end{abstract}

\section{Background}

Type 2 diabetes is a disease affecting Australian adults at a rate described as an 'epidemic'. Treatment usually focuses on patient self-management, which may require daily blood sugar monitoring, oral medications or injectable therapies, and regulating diet and exercise. Health research studies of patient self-management, including those involving type 2 diabetes, have focused largely on individual-centred definitions, though a number of studies, in particular qualitative studies, have indicated the positive role of social relationships and informal social networks.

\section{Design}

Exploratory, qualitative

\section{Methods}

The project focused on 26 patients attending a diabetes centre for clinical consultations with centre staff including doctors, diabetes educators, podiatrists and dietitians. The consultations were observed and audio recorded, followed by semi-structured, audio- 
recorded interviews with the patients and separate interviews with the consulting professional staff.

\section{Results}

Overwhelmingly the patients drew on informal social networks of support to manage the disease. Spouses were significant, sometimes presenting with the patient as a 'team' approach to managing the disease. Sons and daughters also played a significant support role, especially interpreting during consultations and explaining health information. In some cases neighbours and also local community organisations provided informal support. Only 2 patients claimed not to use informal social support.

\section{Conclusions}

Informal social support in patients' self-management of type 2 diabetes was found to be an important factor to be considered by clinicians. The study suggested the need for a more deliberate or pro-active policy to involve patients' family and other informal social networks in treatment programs.

\section{Relevance to clinical practice}

Clinicians may need document and incorporate informal social support in the development and implementation of patient management plans.

\section{Summary box: What does this paper contribute to the wider global clinical community?}

- It provides insights into how people diagnosed with type 2 diabetes manage the disease in their everyday lives. 
- It highlights the important role that informal social networks may play in patients' everyday management of type 2 diabetes.

\section{Keywords}

type 2 diabetes, self-management, health literacy, diabetes literacy, informal social support, social networks

\section{INTRODUCTION}

This paper outlines the findings of a qualitative research project undertaken in a diabetes centre in Australia which has implications at a clinical level for the treatment of people diagnosed with type 2 diabetes, and at a broader conceptual level for an understanding of diabetes literacy, a disease-specific derivative of health literacy. Through analysing the situated perspectives of patients at the diabetes centre and the professional staff who work there, the paper makes the case for greater recognition of the role of the patients' social resources, and in particular informal family and friendship networks, within the prevailing self-management treatment model for type 2 diabetes. Along with this clinical shift to a broader social context, at the conceptual level of diabetes/health literacy the case is made for broadening the focus from individual skills to actively understanding and drawing upon people's collective social networks.

\section{BACKGROUND}

Type 2 diabetes - the 'epidemic' 
In Australia, diabetes has been described as the fastest growing chronic disease condition, increasing at a faster rate than heart disease and cancer, and representing 'the epidemic of the 21 st century' and the biggest challenge confronting Australia's health system (Diabetes Australia 2015). Type 2 diabetes mellitus (T2DM) accounts for $85 \%$ of all diabetes and affects approximately five percent of the Australian adult population, in particular people who are older and have a lower socio-economic status (AIHW: Australian Institute of Health \& Welfare 2014). It is a largely preventable lifestyle disease, with its increased prevalence linked in part to sedentary lifestyles (Reeves et al. 2013) and increased obesity in society (Atlantis et al. 2009). The disease is usually progressive and is associated with a range of co-morbidities including high blood pressure, high cholesterol, heart disease, stroke, depression, vision loss and kidney related disorders (AIHW 2013). The self-management of diabetes may involve lifestyle modifications of food choices, physical activity and exercise, and weight control. Glycemia management may involve oral medications or injectable therapies and ongoing blood sugar monitoring. The disease impacts on many aspects of patients' lives, and the broader social network to which they belong. Carolan et al. (2014) for example highlighted the emotional 'burden' and time impacts on families.

\section{Social relationships and health}

Exploring the role of social relationships more generally in health is not new and comprises a significant area of health research, theory and practice (House et al. 1988, Cohen 2004, Umberson \& Montez 2011, Holt-Lunstad \& Uchino 2015). Many studies attempt to quantify the effects of social relationships on health, finding for example that social networks are likely to promote health through shaping people's daily health behaviours (Martire \& Franks 2014). This is most evident in health behaviours of spouses and close social partners (Meyler et al. 2007). Having said this, health 
outcomes are found to depend a lot on different aspects of social networks - their size, characteristics and the quality of social relationships within them (Martire \& Franks 2014). Loss of social networks as people become older is found to have negative health effects (Bookwala et al. 2014).

Specifically related to diabetes, systematic reviews of intervention studies have revealed mixed results. Van Dam et al. (2005) for example, found little link between 'classic forms of support' - spouses, family and friends, and diabetes control. Other systematic reviews show an increase in the number of studies of the supportive role of healthcare professionals, that is 'formal' social support, but less studies of 'informal' support provided by social networks or family members (Stopford et al. 2013).

Studies of informal caregivers and chronically ill patients indicate the central role of family members in the shift from clinician-centred care to 'self' management support (Piette 2010). This was particularly the case with patients deemed to have lower levels of health literacy, though families could also present barriers to self-management, through, for example, criticism of patients (Rosland et al. 2010).

The literature on interventions and health policy about self-management have tended to focus on individual-centred definitions of self-management, and there is growing recognition of the need to go beyond individual factors to examine the wider social context that includes partners, relatives, friends and neighbours (Vassilev et al. 2011). Recent qualitative studies have reinforced that chronic illness management is not just an individual 'but a collective process' involving social networks that potentially can make a contribution to assisting people with chronic illnesses. Thus social network members can be conceptualised as 'an active extension' of the person with a long term condition 
complementing and adding to their efforts and capacities in completing illness management tasks (Vassilev et al. 2014).

\section{Qualitative approaches}

Qualitative studies of social support are playing an important role in understanding health behaviours within the everyday lives of chronically ill people. Carolan et al. (2014), for example, used focus groups with 22 patients with T2DM to examine how they perceived their illness, their personal journeys, and the complexities of their everyday lives as they tried to manage their diabetes. Their results pointed to the unmet needs for people with T2DM in terms of: emotional support; more informal and less complex information; and support from group sessions including peers and educators. They also suggested that family involvement was critically important.

Hinder and Greenhaigh (2012) added an ethnographic element based mainly on observations ('shadowing' respondents) in natural settings, in-depth interviews, and field notes in their study of 30 patients with diabetes. They made the point that with the high interest in self-management, it was surprising there was little research of selfmanagement in individuals 'going about their daily lives' (p. 2). They concluded that successful self-management was affected by the interaction of influences at three levels: the micro - an individual's dispositions and capabilities; the meso - the key roles of relationships and families; and the macro - the prevailing economic conditions and wider social structures. Not unlike other studies (Vassilev et al. 2011, 2014), they viewed current self-management policy for people with chronic illnesses as narrowly focused on the person with the illness and that person's need to change in terms of their knowledge, attitudes and behaviour. Their findings suggested a broader approach should be taken that included clinicians exploring details of their patients' home, 
work/school and community environments more, and factoring them into 'goal setting' and management plans.

\section{Diabetes literacy as a collective, distributed concept}

Examining how people self-manage their T2DM is strongly associated with the concept of health literacy, which the World Health Organisation (WHO 1998) describes as 'the cognitive and social skills which determine the motivation and ability of individuals to gain access to, understand and use information in ways which promote and maintain good health.' We use the term diabetes literacy in this paper as synonymous with, though a sub-set of, health literacy because it is specific to the one disease. It is a term that has gained some traction in the literature in recent years (Wolff et al. 2009, Black 2012, Van den Broucke et al. 2014). In this paper we link the concept of diabetes literacy with some changing concepts of health literacy over the past decade, together with some of the studies outlined already in this paper that indicate the clinical shift from a focus on individuals to a broader collective process involving social networks.

There are two broad conceptualisations of health literacy, which researchers have variously referred to as 'risk' and personal 'asset' (Nutbeam 2008), 'clinical' and 'public health' (Pleasant \& Kuravilla 2008) or 'medical literacy' and 'health literacy' (Peerson \& Saunders 2009). The former in these various dualisms usually represents the more traditional focus on the cognitive skills individuals need in order to read and understand health texts, as measured by standardised tests such as REALM and TOFHLA. The latter conceptualisations, often representing health promotion perspectives, are more about empowering individuals and communities to exert greater control over their health and the social and environmental determinants of health. Thus health literacy can be viewed in a broader sense as a 'resource' or an 'asset' - having 
the skills to navigate and apply knowledge for health and well-being in everyday contexts. A further developmental element is 'critical health literacy', how people appraise health information and take action for the public good (Chinn, 2011).

Health literacy has become a complex concept and the subject of recent systematic literature reviews (Martensson \& Hensing 2012, Sorenson et al. 2012), often with the aim of developing appropriate health literacy measures. Osborne et al. (2013) have recently developed a broad measure of health literacy capable of diagnosing health literacy needs across individuals and organisations based on a grounded analysis of how people engage with health in their daily experiences. They identify nine conceptually distinct properties that comprise the health literacy of an individual: feeling understood and supported by healthcare providers; having sufficient information to manage my health; actively managing my health; social support for health; appraisal of health information; ability to engage with healthcare providers; navigating the healthcare system; ability to find good health information; and understanding health information well enough to know what to do. Importantly, one of the properties relates to the focus of this paper, social support - drawing on others for assistance.

Another conceptualisation of health literacy has been proposed by researchers who adopt a 'social practices' approach, that is, researchers who are concerned primarily with how health literacy is used and valued in everyday social contexts based on ethnographic methods. Papen $(2009,2012)$ for example, in a qualitative study of the situated perspectives of users of health services, researched how individuals, often lacking skills in a cognitive sense, nevertheless managed to effectively navigate their health care needs using social networks for assistance, including health care professionals and other community organisation representatives. Papen (2009) concludes that health literacy is often 'distributed,' by which she means it is not simply 
a property or an attribute of an individual, but that it is 'shared knowledge and expertise' that resides in the patient's social network. Edwards et al. (2013), using longitudinal qualitative interviews, similarly indicated the role of family members and others acting as 'health literacy mediators' in assisting individuals to manage their long term health conditions. Lloyd et al. (2014) from an 'information literacy' perspective also focused on the role of social relations and health. Using semi-structured interviews to research how people living with chronic health conditions accessed and used health information, they concluded that health literacy is a complex social practice involving information sharing with professional, peers (fellow sufferers) and social affiliations (family, friends). Similarly, a recent qualitative study of the strategies used by older people to obtain health information (McGrath et al. 2015) indicated the significance of how older people use personal social networks in the local community, from family members to librarians and pharmacists.

Thus 'social practice' health literacy studies using qualitative methodologies represent more interpretive and cultural perspectives on health literacy (Zoller \& Dutta 2008, Nimmon 2014). Their focus on the broader social contexts of people's everyday lives resonates with the qualitative studies of self-management outlined earlier that encourage a treatment focus beyond the 'clinical' needs of the patient only.

\section{METHODS}

This study outlines the perspectives of T2DM patients but also of professional staff at a diabetes centre for day patients in a major Australian city. The majority of the patients featured in the study were from culturally and linguistically diverse backgrounds. The project was designed as a qualitative health literacy project which sought to examine the resources patients with T2DM and diabetes centre staff drew upon to maintain the 
health and well-being of patients. Findings from the project were shared with centre staff in a series of workshops at the conclusion of the research with a view to improving clinical and organisational practices at the centre.

\section{The diabetes centre}

Staff at the diabetes centre comprise a team of several doctors specialising in endocrinology, diabetes educators, podiatrists, and a dietitian. Patients are usually referred to the centre by their GP or hospital staff, though patients can also self-refer, usually by contacting the centre directly by phone for an appointment. As part of hospital public health service, the centre's services are free of charge. Patients have varying needs and may be scheduled to see one or a number of the specialist staff during a visit. Typically, a patient may spend approximately an hour with a staff member on an initial visit, and approximately 40 minutes for follow up visits. The centre caters for patients with either type 1 or type 2 diabetes, though the latter was the focus for this project.

\section{Data collection methods and data analysis}

Data were collected from November 2014 to May 2015 and undertaken by two university researchers with a background in adult education.

The research processes and elements comprised the following:

A researcher approached a patient awaiting a consultation at the centre and asked if they would consent to be part of a research study. If the patient agreed they were then provided with written information and a verbal explanation of the research, and asked to consent in writing. 
$>$ The researcher then accompanied the patient, together with support people (spouse for example, and also an interpreter in some cases) to the consultation, where the researcher observed, audio recorded and made field notes of the consultation.

Following the consultation the researcher accompanied the patient to a private area of the centre (often a spare office) for a semi-structured interview regarding the patient's management of diabetes and the role of the centre. This interview was also audio recorded and usually took 20-30 minutes.

Interviews were also conducted with individual centre staff members - doctors, educators, podiatrists and the dietitian at an appropriate time when the staff member was available. These interviews were semi-structured and audio recorded and took approximately 40 minutes each.

Ethics approval for the project was obtained from the Human Ethics Committee of the South Eastern Sydney Local Health District, and the Human Research Ethics Committee at the University of Technology Sydney

The target group for the project was primarily culturally and linguistically diverse patients with T2DM. In some consultations (five in total) interpreters were booked by the centre, and, when the interpreter's time constraints (or allocation) permitted, the researchers used their services for the initial discussion with the patient about the research and obtaining consent, and for the interview following the consultation.

While the research of the consultations was essentially an ethnographic process, as the researcher played no formal role and was placed away from the direct consultation process, the follow-up interviews with patients were semi-structured. Questions in the interviews focused on how well the patients thought they managed their diabetes, what 
resources they accessed, including social support from others, and feedback on the information provided by staff (verbal, written). Staff interviews focused on how they worked with patients, their training and learning experiences, the resources they could access, and the sorts of issues and problems that arose with patients. Audio recordings of consultations and interviews were later transcribed.

For this paper, which focuses on just one aspect of the research, the role of patients' social support, all transcript data and observation notes were extracted and coded relating to who or whether patients used social networks of support in managing their diabetes. The data were organised thematically based on the type of support the patients used - spouses, sons/daughters, other relatives, neighbours, friends and community organisations, external agencies (for example, pharmacists), and also for those who appeared not to access informal social support. Data were also collated on insights on social networks obtained from the transcripts of interviews with the professional staff.

\section{RESULTS}

\section{The patient sample}

A total of $26 \mathrm{~T} 2 \mathrm{DM}$ patients were observed in clinical consultations and later interviewed. There were 16 female and 10 male patients, and the ages ranged from 43 to 85 with a mean age of 65 years. Twenty one of the 26 patients were born overseas where English was not the main language spoken, though 14 patients said they spoke mainly English at home. Five patients used interpreters in their consultations. Countries of birth for the patients were: Australia (4 patients), Bangladesh, Chile, Columbia, Egypt, Fiji, Greece (4), Iran, Italy, Lebanon, Macedonia, Malta, Nepal, New Zealand, Russia (2), Spain, Thailand, Turkey, Ukraine. 
The staff at the centre interviewed for the study included doctors (6), educators (4), podiatrists (2), and one dietitian. All names of patients and staff in this paper are pseudonyms.

\section{The complexities of T2DM and co-morbidities}

The effects of T2DM and the ways that the disease affected the daily living of the patients in the study sample varied considerably. At one end of the spectrum, for example, were patients like Melanie, a 72 year old Greek woman who attended the diabetes centre for the first time for dietary advice following a routine blood test that revealed that she may have diabetes. She was relatively unaffected by the disease. Other patients had been diagnosed with T2DM decades earlier, were on daily insulin injections, and experienced a wide range of co-morbidities, such as 76 year old Russian-born Larisa, first diagnosed 40 years ago. Two patients were diabetes-related amputees: Cesar, a Spanish-born 64 year old who had had several toes amputated, and Sasha, a Macedonian-born 66 year old who had had a leg amputated. Some patients had serious co-morbidities, such as Ashna, 52 years of age and Fijian-born whose health conditions included: severe vision loss, kidney disease, hypertension, ischaemic heart disease, and arthropathy affecting mobility in her hands/arms and legs. Clearly, the nature and severity of T2DM, often in combination with other serious health conditions, was likely to have an influence on how patients managed their daily living, and in turn would influence their need for social support of some kind.

\section{The role of spouses}

Unsurprisingly for a number of patients, their spouse provided the major support role in enabling them to manage with T2DM. Sybil for example, a 78 year old Australian-born woman also had Parkinson's disease and was suffering the effects of a stroke. She 
relied very heavily on her husband David for support both at home, where he did all the cooking and household chores, and in medical consultations where he played an active, mediating role, representing to a large extent her voice. For Sybil and David, living with diabetes was a team effort reflected in constant references David made to 'we' in the consultation with an educator. Other patients also acted together with their spouses, jointly attending consultations, though not always with the same level of team harmony. Maria for example, a 72 year old Maltese-born woman, was irritated in the consultation by her spouse's intrusion on her independence as she learnt to inject insulin ('just leave me to do it' she said). In the case of Peter, an Australian-born 62 year old, his wife played a strong advocacy role in his health. In the consultation with a diabetes educator she resisted the idea that he would soon need insulin injections: 'let's wait until we see the doctor next month to decide about that.' In the cases of both male amputee patients, their spouses played significant roles in their daily living. Cesar, for example, seemed to abrogate most responsibility for knowing how to manage diabetes in favour of his wife (and daughter), stating: 'they understand what doctor tell me, everything.'

While in many cases spouses provided support to patients both at home and in clinical consultations, the home circumstances could be complex, and in one case the spouse was seen to be more as a hindrance. Natascha, a 61 year old Russian-born woman diagnosed with T2DM more than two decades ago, explained that her husband also had T2DM and heart problems. But his refusal to cooperate to improve his health was a constant emotional burden for her:

My husband is not healthy, he eats meat three times per day, he smokes. I am tired of fighting. I try to cook healthy, he does not help me with diet and food ... He does not want to take tablets. He always fights with me. I understand it's no good but I have no power to fight with him. 
Social support from spouses could also have additional emotional costs for the spouses, as the case of Costa, the 69 year old Greek-born patient, demonstrated. He received considerable support from his wife in his daily life, referring to her as his 'memory' during consultations, but this in turn caused her to be badly stressed. She had given up her work to support Costa, but in the process had become overwhelmed: 'I am full time nurse, psychologist, you name it.'

\section{Sons and daughters}

If not the spouse, then the adult children of patients often featured prominently in providing support to them, though sometimes this support was qualitatively different from spouses as the adult children often had the additional responsibilities of managing their own work and family lives. But while they had busy lives of their own, their role was often integral, especially involving issues of cultural and linguistic diversity. For example, patients sometimes attended consultations at the centre with their son/daughter acting as an interpreter for them. With Cesar for example, the Spanish speaking patient with several toes amputated, both his wife and daughter accompanied him for consultations. The daughter's role seemed to be to ensure all aspects of the consultation were understood properly (based on her English language skills), and the wife's role was to put into effect the clinician's instructions in the home environment.

Other patients explained that their sons or daughters transported them to and from medical appointments and provided them with much assistance (with, for example, form filling). Often sons or daughters were living close by and were readily available to provide support, and in other cases they themselves worked in a hospital or medical field so they had knowledge of the health system. In the case of Bahar, an 85 year old Iranian-born patient, it was initially unknown during the consultation that she had any 
access to social support because she lived alone. But at the very end of the consultation she was asked for a contact number for a follow up visit, and she suggested her daughter, a registered nurse, or her daughter-in-law, a doctor, both of whom lived nearby.

As with spouses however, children were not always in a position to provide patients with the support they may need. Penny (Penelopeia), for example, a 57 year old Greek woman, had an 18 year old son living at home with her who has autism, and her granddaughter has an intellectual disability. In Penny's case, she needed to be the one providing support, as she explained, her family were very close-knit and 'I've got to be healthy' in order to look after them.

\section{Other relatives, neighbours, friends and community organisations}

Ria from New Zealand was in such poor health with heart problems, daily haemodialysis and constant blood glucose monitoring, that she received intensive support from her three nieces, and on occasions from her 17 year old grand-niece who often stayed with her. As Ria explained: 'she watches me throughout the day, and I tell her if something's wrong ... she's the one who goes 'doonk', straight onto the phone to the other nieces.' Aspects of Ria's daily life such as buying and cooking food were regulated by her nieces, acting in her interests, 'cos they know what I'm like, so they kind of take their control over me ...' Ria's case is an interesting example of a reciprocal kinship pattern in which her nieces were now looking after her, though many years ago 'when they were all babies I used to watch them ... while their parents were out partying.'

Neighbours also featured as important support networks, especially if immediate family members were not available. Ashna, the Fijian-born patient with serious vision, kidney, 
heart disease and arthropathy problems was a good example of this. She lived in a public housing unit and frequently called on the help of her 81 year old neighbour, a South African man. He sometimes accompanied her to consultations at the diabetes centre in case she felt dizzy on the journey there and back. It was this neighbour who helped Ashna to learn to self-inject insulin, and he also read letters for her. But the support was sometimes reciprocated. As Ashna explained: 'One day he fall down in the bathroom. He broke his leg, fall down, I been there ... I just call the ambulance.'

Another important form of social support was described by Penny, the Greek woman mentioned previously who was anxious to maintain her health so that she could assist her own family, especially her autistic son and intellectually disabled grand-daughter. Her own support came not from her family members but from a Greek-speaking carers group for people with disabilities or mental health issues. Penny described how this carers group had helped her for the past 10 years:

It's the best thing in my life ... I'm a different person now, because of the group ... There are ten women in that group, we are like sisters. We talk about our children who have disability or mental health issues ... We discuss everything in the group - they are interested to hear about my diabetes, going on insulin. This is my support group, not only as carers.

The final types of social support mentioned by the patients were those linked to an organisation of some kind. For example, in the case of Ashna, when she needed information read to her, and her elderly neighbour was not available, she knew people in the local shopping centre and the local legal aid centre who were always happy to assist her. Pharmacists and doctor's receptionists were also mentioned as sources of support. 


\section{Patients without social support}

Not all of the patients had important social support networks, at least not ones that were readily available. Jimmy, for example, was a 64 year old Australian-born man who had been attending the diabetes centre for over 20 years, and had just started insulin injections. He lived alone, with no family or friends nearby for support with his diabetes or other medical conditions (including a recent triple heart by-pass and knee replacements). Similarly with Alejandro, a 63 year old man originally from Columbia and also on insulin. His estranged wife and children lived in the UK, though he was enjoying having his son stay with him at the time of the interviews. He worked as a cleaner, and beyond his visits to the diabetes centre, he claimed he never spoke to anyone about his diabetes. But patients like Jimmy and Alejandra with little or no social support appeared to represent only a small minority of patients at the diabetes centre.

\section{Independence within families}

In some cases patients may have had ready support if needed, but they were deliberately resolved to be independent in their management of T2DM. Hala for example, was 53 years old and born in Lebanon. She lived at home with her husband (who used a wheelchair as the result of an accident, but was quite mobile and supportive) and her 21 year old son. She had recently received a kidney transplant and was then diagnosed with T2DM, but for years she had independently managed her own health ('I do dialysis by myself ... hemodialysis, six years') and she was determined to continue to be independent. Dianne also was independent, an Italian-born 59 year old who had only recently been diagnosed with T2DM. She was a teacher by profession and had long cared for her mother, also a diabetic. Thus she was knowledgeable about T2DM and 
only required dietary advice from the centre and the mental strength to maintain her diet regime.

\section{Professional insights on social networks}

The professional health staff at the centre all commented in various ways on the social support networks of patients, mostly promoting them. For example, one staff member explained: 'I'm amazed to see who comes in with the patient ... I've had people say they get the letter from the hospital about their appointment and they take it next door. It's great, amazing.' Another staff member explained the importance of focusing on the social life of patients because T2DM, unlike many other medical conditions, 'is really about what the patient is experiencing in life and everyday ... every stress, every action that they take really impacts on their diabetes.' This staff member reinforced the value of concentrating 'not so much on sugar levels as such, but putting a lot more emphasis on their social circumstances, and I think a lot of us do that I hope.' She further stated the importance of explaining food and diet not only to the patient but to the person responsible for shopping and preparing food in the home environment.

Several of the professional staff did express some reservations over aspects of social network support. Interpreting during a consultation for example, could be seen as problematic if it was undertaken by a family member, mainly because it was unclear that the untrained family member was both understanding and conveying accurately what the staff member was saying. One staff member suggested that perhaps ideally it should be family members and interpreters together in the consultation, 'then you get an official version and you get corroboration.'

One of the staff members encouraged a role for sons and daughters in consultations, but lamented that they were often too busy to attend. Another staff member expressed 
mixed feeling about the role of spouses in consultations. She had found for example that some men diagnosed with T2DM became disengaged in the consultation, "while his wife leans forward.' In other words, the husband was abrogating his responsibilities in favour of his wife, and thus the staff member occasionally had to asked the wife to leave the consultation because 'I want him to get the message it's his problem not hers.'

On the whole the observations of the consultations between staff and patients indicated professional staff were happy to accommodate family members in the consultations (notwithstanding some of the issues raised above). However, it was not always routinely addressed or encouraged. Patients were not requested to bring along a family member or friend, either at the time of an initial telephone appointment or in follow-up visits, and there was little evidence that professional staff knew about or actively drew on informal support networks as a resource. Perhaps not surprisingly, the consultations overwhelmingly focused on the clinical aspects such as how individual patients understood diabetes and could better control their glucose levels. This focus however, was dictated in large part through the time constraints of appointment times which were at the most one hour.

\section{DISCUSSION}

From the examples of the patients provided in this paper, it is clear that issues involving the role and significance of informal social support for patients with T2DM are complex, and vary considerably across both the patient sample and the views of professional staff at the diabetes centre. But it is also clear that informal social support of some kind features in most of the patients' daily lives, especially given the 'everyday' nature of the disease that almost inevitably leads it to affecting relations with others, family in particular. For a number of these patients such was their reliance 
on informal social support that the term self-management was not necessarily the case because their diabetes management was essentially undertaken by others within their family or close relations. For example, Spanish speaking patient Cesar who had had toes amputated, stated his wife and daughter understood 'everything' the doctors said, and they took complete responsibility for his care, including daily insulin medications, changing his foot dressings, food preparation and navigating the health system for appointments. Similarly Sybil, who had had a stroke and was suffering Parkinson's disease, relied almost entirely on her spouse to manage diabetes in her daily life. For these two patients and for others in the patient sample, informal social support from family and sometimes other relatives and neighbours could be viewed, as Vassilev et al. (2014) described it, 'as an active extension of the person' with the chronic condition.

Not all informal social networks had a positive influence on how individual patients managed their diabetes, and this corresponds with some of the research literature (Rosland et al. 2010). Natascha's husband for example, was uncooperative and argumentative, affecting her emotional well-being and self-care. But for most of the patients in this study, informal social networks had a positive influence, except that it is worth recalling the case of 69 year old Costa, whose wife had given up work to care for him - she found the stresses of this role had a negative effect on her health and emotional well-being.

One of the doctors suggested, because of the 'everyday' nature of the disease which made it different to many other diseases, that professional/clinical staff should, in addition to a clinical focus on sugar levels, focus on the social circumstances of the patient. But there was little evidence of clinicians actively promoting the potential role of the informal social networks in managing the patients' diabetes. These findings correspond with the some of the qualitative studies cited earlier that suggest the value of 
incorporating broader social contexts in understanding and managing health (Hinder \& Greenhaigh 2012, Vassilev et al. 2014).

Traditionally, concepts of health literacy do not encourage a focus beyond the knowledge and skills of individuals, and many definitions of health literacy refer specifically to individuals (e.g. WHO 1998). But as we have seen, some patients in our study performed little self-management (Piette 2010), with the dominant disease management role being undertaken by family members. Also, in one case, a family member (spouse) played a dominant negative role in a patient's health, as with Natascha and her argumentative and uncooperative husband. Thus informal social support can be a significant enabler and also inhibitor of health/diabetes literacy. While all patients varied in their need for, and the extent to which they received informal social support in managing their diabetes, the study findings encourage the argument that social support should be elevated in conceptualisations of health literacy. Such a line of argument corresponds with the work of 'social practice' researchers such as Papen (2009) who advocate the view that health literacy is 'distributed,' that it is not simply the property of an individual but is 'shared knowledge and expertise.' It is a collective concept that resides in the patient's family and other social networks in the community.

\section{CONCLUSIONS}

There were of course limitations to this research study - it was a small scale, local qualitative study, and it focused on the meso level - dealing with the key roles of relationships and family (see Hinder \& Greenhaigh 2012). It did not examine in any detail micro level aspects such as the individual dispositions and capabilities of patients (including for example, their individual agency, or their cognitive abilities). It also did 
not examine macro factors - the broader social and environmental determinants of health, including the effects of low socio-economic status.

But despite these limitations, the study's findings can be seen to add to the research evidence that social resources, and in particular, informal social support, are potentially significant at the clinical level for treatment of T2DM and for the concept of diabetes literacy. It is not that social support is ignored in the literature, as demonstrated in recent systematic reviews of health literacy (Sorenson 2012) and it comprises one of the key health literacy properties identified by Osborne et al. (2013). But as this study has indicated, for some patients at least, social support is a significant enabler/inhibitor of how they manage their diabetes.

\section{RELEVANCE TO CLINICAL PRACTICE}

For clinical practice, the study findings imply the need for a more deliberate or proactive policy to involve patients' family and other informal support networks in treatment programs, possibly from the time of initial referral to centres such as the diabetes centre featured in this study. Informal social support may need to be more prominent in clinical procedures and be included in the development and implementation of patient management plans. And this clinical focus on the broader social context could be encouraged at all health professional levels if social support seen as 'shared knowledge and expertise' is to occupy a more salient role in conceptualisations of health/diabetes literacy.

\section{REFERENCES}

Atlantis E, Lange K \& Wittert GA (2009) Chronic disease trends due to excess body weight in Australia. Obesity Reviews 10, 543-553. 
AIHW: Australian Institute of Health and Welfare (2013) Diabetes and disability: Impairments, activity limitations, participation restrictions and comorbidities. AIHW, Canberra.

AIHW: Australian Institute of Health and Welfare (2014). Cardiovascular disease, diabetes and chronic kidney disease: Australian facts: prevalence and incidence. AIHW, Canberra.

Black S (2012) Diabetes literacy: Health and adult literacy practitioners in partnership. Australian Journal of Adult Learning 52, 89-113.

Bookwala J, Marshall KI \& Manning SW (2014. Who needs a friend? Marital status transitions and physical health outcomes in later life. Health Psychology 33, 505515.

Carolan M, Holman J, \& Ferrari M (2014) Experiences of diabetes self-management: A focus group study among Australians with type 2 diabetes. Journal of Clinical Nursing 24, 1011-1023.

Chinn D (2011) Critical health literacy: A review and critical analysis. Social Science \& Medicine 73, 60-67.

Cohen S (2004) Social relationships and health. American Psychologist 59, 676-684.

Diabetes Australia (2015) Diabetes in Australia. Available at: https://www.diabetesaustralia.com.au/diabetes-in-australia (accessed 9 February 2016).

Edwards M, Wood F, Davies M \& Edwards, A (2013) Distributed health literacy: Longitudinal qualitative analysis of the roles of health literacy mediators and social networks of people living with a long-term health condition. Health Expectations: An International Journal of Public Participation in Health Care and Health Policy 12. 
Hinder S \& Greenhaigh T (2012) 'This does my head in': Ethnographic study of selfmanagement by people with diabetes. BMC Health Services Research 12.

Holt-Lunstad J \& Uchino N (2015) Social support and health. In Health behavior: Theory, research, and practice (Glanz K, Rimer BK \& Viswanath K eds.). Jossey Bass, San Francisco, pp. 183-214.

House JS, Landis KR \& Umberson D (1988). Social relationships and health. Science 241, $540-45$.

Lloyd A, Bonner A \& Dawson-Rose C (2014) The health information practices of people living with chronic health conditions. Journal of Librarianship and Information Science 46, 207-216.

McGrath M, Clancy K \& Kenny A (2015) An exploration of strategies used by older people to obtain information about health- and social care services in the community. Health Expectations, Early View DOI: 10.1111/hex.12408

Martensson L \& Hensing G (2012) Health literacy - a heterogeneous phenomenon: A literature review. Scandinavian Journal of Caring Sciences 26, 151-160.

Martire L \& Franks M (2014) The role of social networks in adult health: Introduction to the special issue. Health Psychology 33, 501-504.

Meyler D, Stimpson JP \& Peek MK (2007) Health concordance within couples: A systematic review. Social Science and Medicine 64, 2297-2310.

Nimmon LE (2014) Meaning making within the social activity domain of health maintenance: The role of social networks. PhD thesis, University of British Columbia, Vancouver.

Nutbeam D (2008) The evolving concept of health literacy. Social Science \& Medicine 67, 2072-2078. 
Osborne R, Batterham R, Elsworth G, Hawkins M \& Buchbinder R (2013) The grounded psychometric development and initial validation of the health literacy questionnaire (HLQ). BMC Public Health 13, 658.

Papen U (2009) Literacy, learning and health: A social practices view of health. Literacy and Numeracy Studies 16/17, 19-34.

Papen U (2012) Informal, incidental and ad hoc: The information-seeking and learning strategies of health care patients. Language and Education 26, 105-119.

Peerson A \& Saunders M (2009) Health literacy revisited: What do we mean and why does it matter? Health Promotion International 24, 285-296

Piette J (2010) Editorial: Moving beyond the notion of 'self' care. Chronic Illness 6, 3-6.

Pleasant A \& Kuruvilla S (2008) A tale of two health literacies: Public health versus clinical approaches to health literacy. Health Promotion International 23, 152-159.

Reeves MM, Healy GN, Owen N, Shaw JE, Zimmet PZ \& Dunstan DW (2013). Joint associations of poor diet quality and prolonged television time with abnormal glucose metabolism in Australian men and women. Preventive Medicine 57, 471476.

Rosland AM, Heisler M, Choi HJ, Silviera MJ \& Piette JD (2010). Family influences on self-management among functionally independent adults with diabetes or heart failure: Do family members hinder as much as they help? Chronic Illness 6, 22-33. Sorenson, K., Van den Broucke, S., Fullam, J., Doyle, G., Pelikan, J., Slonska, Z., \& Brand, H. (2012). Health literacy and public health: A systematic review and integration of definitions and models. BMC Public Health, 12:80.

Stopford R, Winkley K \& Ismail K (2013) Social support and glycemic control in type 2 diabetes: A systematic review of observational studies. Patient Education \& Counseling 93, 549-558. 
Umberson D \& Montez JK (2010) Social relationships and health: A flashpoint for health policy. Journal of Health and Social Behaviour 51, S54-S66.

van Dam HA, van der Horst FG, Knoops L, Ryckman RM, Crebolder HF \& van den Borne BH (2005) Social support in diabetes: A systematic review of controlled intervention studies. Patient Education Counseling 59, 1-12.

Van den Broucke S, Van der Zanden G, Chang P, Doyle G, Levin D, Pelikan J, Schillinger D, Schwartz P, Sorenson K, Yardley L \& Riemenschneider H (2014) Enhancing the effectiveness of diabetes self-management education: The diabetes literacy project. Hormone and Metabolic Research 46, 933-938.

Vassilev I, Rogers A, Sanders C, Kenneday A, Blickem C, Protheroe J ... Morris R (2011) Social networks, social capital and chronic illness self-management: a realist review. Chronic Illness 7, 60-86.

Vassilev I, Rogers A, Kennedy A \& Koetsenruijter J (2014) The influence of social networks on self-management support: A metasynthesis. BMC Public Health 14, 719.

World Health Organisation (1998) Health Promotion Glossary. Health Promotion International 13, 349-364.

Wolff K, Cavanaugh K, Malone R, Hawk,V, Gregory BP, Davis D, Wallston K \& Rothman RL (2009) The Diabetes Literacy and Numeracy Education Toolkit (DLNET): Materials to facilitate diabetes education and management in patients with low literacy and numeracy skills. The Diabetes Educator 35, 233-6, 238-41, 244-5.

Zoller H \& Dutta MJ (eds) (2008) Emerging perspectives in health communication: Meaning, culture, and power. Routledge, New York. 